\title{
Heterologous production of resveratrol in bacterial hosts: current status and perspectives
}

\author{
A. Braga ${ }^{1} \cdot$ P. Ferreira ${ }^{1} \cdot$ J. Oliveira ${ }^{1} \cdot$ I. Rocha $^{1,2} \cdot$ N. Faria ${ }^{1}$
}

Received: 5 June 2018 / Accepted: 19 July 2018

○) Springer Nature B.V. 2018

\begin{abstract}
The polyphenol resveratrol (3,5,4'-trihydroxystilbene) is a well-known plant secondary metabolite, commonly used as a medical ingredient and a nutritional supplement. Due to its health-promoting properties, the demand for resveratrol is expected to continue growing. This stilbene can be found in different plants, including grapes, berries (blackberries, blueberries and raspberries), peanuts and their derived food products, such as wine and juice. The commercially available resveratrol is usually extracted from plants, however this procedure has several drawbacks such as low concentration of the product of interest, seasonal variation, risk of plant diseases and product stability. Alternative production processes are being developed to enable the biotechnological production of resveratrol by genetically engineering several microbial hosts, such as Escherichia coli, Corynebacterium glutamicum, Lactococcus lactis, among others. However, these bacterial species are not able to naturally synthetize resveratrol and therefore genetic modifications have been performed. The application of emerging metabolic engineering offers new possibilities for strain and process optimization. This mini-review will discuss the recent progress on resveratrol biosynthesis in engineered bacteria, with a special focus on the metabolic engineering modifications, as well as the optimization of the production process. These strategies offer new tools to overcome the limitations and challenges for microbial production of resveratrol in industry.
\end{abstract}

Keywords Bacteria $\cdot$ Malonyl-CoA $\cdot$ Metabolic engineering $\cdot$ Pathway engineering $\cdot$ Resveratrol

\section{Introduction}

Resveratrol (3,5,4'-trihydroxystilbene) is a well-characterized plant derived polyphenol, which is commonly used as a nutritional supplement and medicinal ingredient (Baur and Sinclair 2006). Resveratrol was first isolated from white hellebore, Veratrum grandiflorum, in 1939 (Takaoka 1939) and was initially characterized as a phytoalexin (Takaoka 1939; Bauer et al. 2004). Later it has been found in extracts of the roots of Japanese knotweed, Polygonum cuspidatum, which is a Chinese herbal medicine and now the main source for commercial resveratrol (Nonomura et al. 1963). Subsequently, resveratrol was also shown to be present in grapevine Vitis vinifera (Baur and Sinclair 2006) and berry fruits,

$\triangle$ A. Braga

abraga@deb.uminho.pt

1 Centre of Biological Engineering, University of Minho, Campus de Gualtar, 4710-057 Braga, Portugal

2 Instituto de Tecnologia Química e Biológica, Universidade Nova de Lisboa, Av. da República, 2780-157 Oeiras, Portugal such as blackberries, blueberries and raspberries (Kiselev 2011).

After resveratrol discovery, a lot of studies have showed its health benefits in preclinical studies and in human trials (Hubbard and Sinclair 2014). The first studies in human trials reported its antioxidant capacity, showing that resveratrol can impede low-density lipoprotein (LDL) oxidation by chelating copper (Frankel et al. 1993) and also prevents the lipid peroxidation (Blond et al. 1995). It was hypothesized that the low incidence of cardiovascular diseases in the French population might be related with the resveratrol, despite their high consumption of saturated fatty acids (also known as "French paradox") (Yang et al. 2014). Besides antioxidant properties, resveratrol also blocks a number of different types of cancer, in preclinical studies (Aggarwal et al. 2004; Kundu and Surh 2008), provides some protection against diabetes (preclinical studies with animal models) (Sharma et al. 2007) and neurodegenerative diseases such as Alzheimer's (preclinical studies with cell lines and animal models) (Anekonda 2006; Wang et al. 2006; Vingtdeux et al. 2008). Recently, resveratrol has been shown to enhance 
the longevity of several species, accessing its potential as an anti-aging agent in treating age-related human diseases (preclinical studies with animal models and cell cultures) (Bauer et al. 2004; Viswanathan et al. 2005).

Currently, most of resveratrol available on the market is produced in China by extraction from plants, such as $P$. cuspidatum (Liu et al. 2016). Unfortunately, in many cases, the low abundance of polyphenols in plants hinders their extraction in sufficient amounts since they are only produced in response to stress situations or infections (Bavaresco et al. 1997). Also, environmental and geographic factors lead to a constant shortfall of product supply from natural sources. Furthermore, the extraction process is also difficult since the plants extracts have a mixture of chemically very similar polyphenols and the isolation of individual compounds is a challenge. In fact, chemical synthesis is also a widely reported method for resveratrol production with high yield, whereas the application of this technique is greatly limited due to the complexity of the synthesis process and the production of undesirable side products (Quideau et al. 2011). Considering the drawbacks and issues of the natural extraction or chemical synthesis of resveratrol, its microbial production is an interesting alternative and has been attracted a great deal of research interest. Microbial resveratrol biosynthesis has several advantages, since microorganisms have very rapid production cycles, reach high biomass yields and can be cultivated in defined media in scalable production processes. The first study on microbial production of resveratrol was achieved in yeast (Beekwilder et al. 2006). Afterward, several studies were performed and the resveratrol production was improved in yeast [with resveratrol titers between 3.1 and $812 \mathrm{mg} \mathrm{L}^{-1}$ (Shin et al. 2011; Li et al. 2016)] and bacteria [resveratrol concentrations between 1.4 and $2.34 \mathrm{~g} \mathrm{~L}^{-1}$ (Lim et al. 2011; Choi et al. 2011)] by the introduction and expression of natural plant pathways and engineering of the microbial host metabolism towards increased production (Beekwilder et al. 2006; Yang et al. 2015).

This mini-review provides an overview of the research that has been done recently on the heterologous resveratrol production with bacterial hosts, discussing the new tools and strategies at gene, protein and pathway levels, as well as optimization of the fermentation process for its efficient biosynthesis.

\section{Resveratrol biosynthesis pathway}

The bioproduction of resveratrol is initiated from phenylpropanoid acids including cinnamic acid and $p$-coumaric acid that are derived from aromatic amino acids.

The amino acids biosynthesis starts with the enzyme 3-deoxy-D-arabino-heptulosonate-7-phosphate (DAHP) synthase that catalyzes the condensation of phosphoenolpyruvate (PEP) and erythrose-4-phosphate (E4P) to form DAHP (Fig. 1). In bacteria, DAHP synthase occurs as three isoforms, each one regulated by feedback-inhibition allosteric mechanism (Light et al. 2012). Six enzymatic reactions convert DAHP to chorismate $(\mathrm{CHO})$, the precursor of L-phenylalanine (L-Phe) and L-tyrosine (LTyr) (Maeda and Dudareva 2012). These aromatic amino acids are the final products of most bacteria biosynthetic pathways. Nevertheless, in plants and some bacteria, these amino acids are intermediates in pathways for the synthesis of secondary metabolites, such as phenylpropanoids. In the first step of phenylpropanoids synthesis, L-Phe and L-Tyr are converted to the phenylpropanoid acids cinnamic acid and $p$-coumaric acid, respectively, via phenylalanine ammonia lyase (PAL) and tyrosine ammonia lyase (TAL), which are then converted to cinnamoyl-CoA and $p$-coumaroyl-CoA by 4-coumarate-CoA ligase (4CL). Cinnamic acid can also be hydroxylated by cinnamate-4-hydroxylase $(\mathrm{C} 4 \mathrm{H})$ to form $p$-coumaric acid. Then three molecules of malonyl-CoA are condensed with one molecule of 4-coumaroyl-CoA by stilbene synthase (STS) yielding one molecule of resveratrol (van Summeren-Wesenhagen and Marienhagen 2015; Milke et al. 2018) (Fig. 1).

\section{Bacterial hosts for resveratrol production}

Microorganisms have been used for a long time in the production of value-added compounds with numerous applications (Du et al. 2013). Since resveratrol is not naturally produced by microorganisms, the genetic engineering of the host strain by functional integration of the heterologous pathways from plants is required. This represents an alternative strategy and has achieved remarkable progress in resveratrol bioproduction (Halls and Yu 2008; Mei et al. 2015).

The choice of the host organism is often a major and first deciding factor in process optimization. Bacterial systems have some advantages compared with yeasts such as traditionally being easier to manipulate, having short doubling time, higher growth rates, and the ability to overexpress high quantities of proteins and enzymes (Makrides 1996; Wu et al. 2013). Also, in contrast with yeast which are sensitive to high concentrations of $p$-coumaric acid, bacteria are much more tolerant to phenylpropanoid acids (Shin et al. 2011; Huang et al. 2013). However, one of the disadvantages of using bacteria as an expression host arises from its inability to perform post-translational modifications, which are often required for correct folding and functional activity of the recombinant protein (Rosano and Ceccarelli 2014). Depending on the properties of the desired compound the use of yeast, such as S. cerevisiae, can be preferable (Yesilirmak and Sayers 2009). S. cerevisiae which is also easy to grow and manipulate and is 


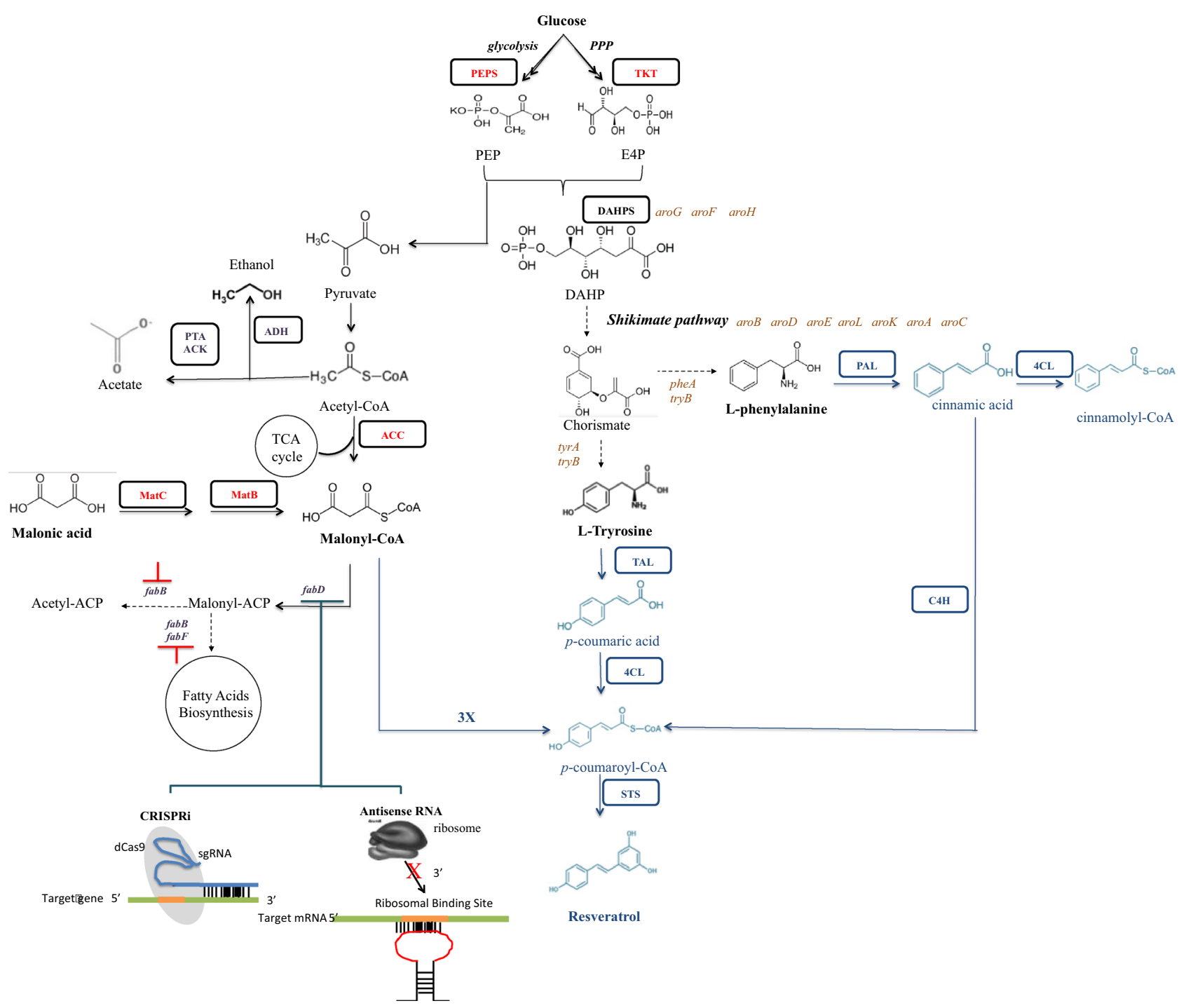

Fig. 1 Schematic representation of the overall pathway for resveratrol production in bacteria: PPP: pentose phosphate pathway; PEPS: phosphoenolpyruvate synthase; TKT: transketolases; E4P: erythrose 4-phosphate; PEP: phosphoenolpyruvate, DAHPS: DAHP synthase (encoded by the gene aroH, aroG, aroF); DAHP: 3-deoxy-D-arabinoheptulosonate 7-phosphate, ADH: alcohol dehydrogenases; PTA: phosphate acetyltransferase; ACK: acetate kinase; TAL: tyrosine ammonia lyase; PAL: phenylalanine ammonia lyase; 4CL: 4-coumarate: CoA ligase; STS: stilbene synthase; $\mathrm{C} 4 \mathrm{H}$ : Cinnamate 4-hydroxylase; ACC: acetyl-CoA carboxylase; tyrA/pheA: gene that encodes the chorismate mutase protein, $\operatorname{tyr} B$ : gene that encodes the tyrosine aminotransferase; aroA: gene that encodes the 3-phosphoshikimate-1-carboxyvinyltransferase protein; aroB: gene that encodes the dehydroquinate synthase protein, aro $C$ : gene that encodes the chorismate synthase protein; aroD: gene that encodes the dehydroqui-

well characterized, presents some unique advantages over bacteria for the production of resveratrol. It has a foodgrade status (GRAS organism), and does not lack the posttranslational machinery like E. coli, having intracellular compartments similar to those of plant cells (Jiang et al. nate dehydratase protein; aroE: gene that encodes the shikimate dehydrogenase protein; aroK/aroL: gene that encodes the shikimate kinase isoenzymes I/II; aroG/aroF/aroH: gene that encodes the DAHP synthase protein; $f a b B / f a b F$ : gene that encodes the beta-ketoacyl-acp synthase I/II protein; $f a b D$ : gene that encodes the malonyl-CoA-acyl carrier protein transacylase; matB: gene that encodes the malonylCoA synthetase protein; matC: gene that encodes the dicarboxylate carrier protein; $s g R N A$ : single guide RNA. The endogenous metabolism is presented at black color (enzymes and intermediates) and heterologous pathway for resveratrol production is indicated in blue (enzymes and intermediates). Enzymes denoted as red indicate overexpression targets, and genes denoted as purple indicated knockout genes. Genes denoted as orange indicate genes in the aromatic amino acid biosynthetic pathway Reproduced with permission from van Summeren-Wesenhagen and Marienhagen (2015), Milke et al. (2018)

2005; Liu et al. 2016). Also, membrane proteins such as cytochrome $\mathrm{P} 450$ would be more adequately expressed in a eukaryotic organism (Rodrigues et al. 2015). Nevertheless, the application of yeast as producing hosts presents some limitations such as low yields compared with bacteria and 
cell stress due to the presence of the foreign genes (Yesilirmak and Sayers 2009; Liu et al. 2016).

Several studies have reported the successful expression of the heterologous biosynthetic pathway for resveratrol production in bacteria, such as Escherichia coli, Lactococcus lactis and Corynebacterium glutamicum, and in yeasts, such as $S$. cerevisae. The first attempt to produce resveratrol in S. cerevisae was described by Beekwilder et al. (2006) who obtained a resveratrol production of $5.8 \mathrm{mg} \mathrm{L}^{-1}$. Different studies have been performed but the resveratrol titers achieved are usually lower than with bacteria [around $812 \mathrm{mg} \mathrm{L}^{-1}$ (Li et al. 2016)] (Table 1). E. coli is one of the well-characterized microorganisms used as microbial platform for industrial applications. The fast growth, easy genetic manipulation and existence of several synthetic biology tools are some of the reasons for E. coli applicability as host for resveratrol production (Theisen and Liao 2016; Wang et al. 2018). However, L. lactis and $C$. glutamicum are organisms with generally-regarded as safe (GRAS) status able to produce compounds with addedvalue importance in food and pharmaceutical industries. These microorganisms also hold genetic tools to be used for metabolic engineering to produce several plant-derived natural compounds. Gaspar et al. (2016) and Kallscheuer et al. (2016) demonstrated that L. lactis and C. glutamicum, respectively, are able to produce resveratrol, showing the assembly and functional expression of synthetic pathways for resveratrol production. Another bacterium described for resveratrol production is Streptomyces venezuelae. This gram-positive bacterium has the capacity to produce a wide range of secondary metabolites and Park et al. (2009) engineered it in order to produce plant-specific compounds, namely flavonoids and stilbenes.

Table 1 presents the studies using yeast and bacteria to produce resveratrol, specifying the introduced genes, the precursors and other components supplemented in culture medium.

The resveratrol titers produced by engineered bacteria are strongly influenced by cell viability, gene expression and plasmid stability. Several efforts have been made to increase gene expression, enhance the precursors availability and improve the intracellular pool of malonyl-CoA by genetically modifying the host. This leads to the optimization of the operational conditions, such as mode of operation (batch, fed-batch and continuous) and environmental conditions (temperature, $\mathrm{pH}$, dissolved oxygen, substrate and cell concentration), in order to increase the final resveratrol titers (Wang et al. 2018).

\section{Metabolic engineering}

Metabolic engineering of microorganisms for resveratrol production has achieved great progress in recent years (Milke et al. 2018; Wang et al. 2018). Nevertheless, the main bottlenecks for microbial resveratrol production are the precursor availability and low stilbene synthase activity in the heterologous hosts. Hence, the main strategies for increasing productivity using microbial cell factories are increasing the precursor supply (aromatic amino acids and malonyl-CoA) via genetic manipulation of the strain and improving the activity of key enzymes via protein engineering (van Summeren-Wesenhagen and Marienhagen 2013; Milke et al. 2018).

\section{Enzyme selection and protein engineering}

The successful design of a biosynthetic pathway for resveratrol production depends in a great extent on the use of appropriate synthetic enzymes. Resveratrol production can be improved by exploring alternative enzymes from other sources that allow higher resveratrol yield or more specific enzymes that allow production of the desired compound with fewer by-products.

Watts et al. (2006) used an engineered E. coli strain BW27784 harboring 4CL from Arabidopsis thaliana and a STS from Arachis hypogea and achieved a resveratrol production of $104.5 \mathrm{mg} \mathrm{L}^{-1}$, with the supplementation of $p$-coumaric acid. A. thaliana $4 \mathrm{CL}$ was recently shown to preferentially use ferulic acid and sinapic acid as substrates (Hamberger and Hahlbrock 2004). A. hypogea STS has been reported to have a broad substrate specificity (Morita et al. 2001; Abe et al. 2004). In the same conditions Beekwilder et al. (2006) and Zhang et al. (2015) obtained a resveratrol production of 80.52 and $16 \mathrm{mg} \mathrm{L}^{-1}$, respectively, using another $E$. coli strain, E. coli BL21. Lim et al. (2011) achieved a resveratrol production of $2.39 \mathrm{~g} \mathrm{~L}^{-1}$ with an $E$. coli strain BW27784 harboring 4CL from A. thaliana and STS from $V$. vinifera, in the presence of $15 \mathrm{mM} p$-coumaric acid and cerulenin. It has been demonstrated that $A t 4 \mathrm{CL}$ was functional in recombinant $E$. coli for flavonoid productions (Watts et al. 2006) and that STS from V. vinifera allowed a higher resveratrol titer when compared with other STS tested (Lim et al. 2011). Nevertheless, Wu et al. (2013) cloned TAL from the red yeast Rhodotorula glutini, 4CL from Petroselinum crispum and STS from V. vinifera, in different $E$. coli strains, but the resveratrol titers obtained were very low. $R$. glutini TAL was reported to have the highest specific activity for L-Tyrosine (Vannelli et al. 2007; Schroeder et al. 2008). 4CL from P. crispum and STS from $V$. vinifera were chosen as they had been successfully used in previous studies to achieve the highest production of resveratrol from $p$-courmaric acid (Lim et al. 2011). Kallscheuer et al. (2016) engineered a C. glutamicum strain for resveratrol production with STS from peanut (A. hypogaea), based on the work from Watts et al. (2006), and 4CL from parsley (P. crispum), since it had a more diverse substrate specificity than other 4CL enzymes 
Table 1 Biosynthesis of resveratrol in bacteria

\begin{tabular}{|c|c|c|c|c|c|}
\hline Microorganism & $\begin{array}{l}\text { Heterologous enzymes/ } \\
\text { gene (source) }\end{array}$ & Host engineering & Substrate/precursor & Titer $\left(\mathrm{mg} \mathrm{L}^{-1}\right)$ & References \\
\hline E. coli BW27784 & $\begin{array}{l}\text { 4CL }(\text { A. thaliana }) \\
\text { STS }(\text { A. hypogaea })\end{array}$ & - & $p$-Coumaric acid & 0.160 & Afonso et al. (2015) \\
\hline $\begin{array}{l}\text { E. coli } \\
\text { BL21 }\end{array}$ & $\begin{array}{l}\text { 4CL (Nicotiana taba- } \\
\text { cum) } \\
\text { STS }(V . \text { vinifera })\end{array}$ & - & $p$-Coumaric acid & 16 & Beekwilder et al. (2006) \\
\hline $\begin{array}{l}\text { E. coli } \\
\text { BRB }\end{array}$ & $\begin{array}{l}\text { 4CL }(\text { Lithospermum } \\
\text { erythrorhizon }) \\
\text { STS }(\text { A. hypogaea }) \\
\text { ACC }(\text { C. glutamicum }) \\
\text { F3H and FLS }(\text { Citrus })\end{array}$ & - & $\begin{array}{l}\text { Cinnamic acid } \\
p \text {-Coumaric acid }\end{array}$ & $\begin{array}{l}155 \\
171\end{array}$ & Katsuyama et al. (2007) \\
\hline E. coli BW27784 & $\begin{array}{l}\text { 4CL }(\text { A. thaliana }) \\
\text { STS }(\text { A. hypogaea })\end{array}$ & - & $p$-Coumaric acid & 105 & Watts et al. (2006) \\
\hline \multirow[t]{5}{*}{ E. coli BW27784 } & $\begin{array}{l}\text { 4CL }(\text { A. thaliana }) \\
\text { STS }(\text { A. hypogaea })\end{array}$ & - & $p$-Coumaric acid & 404 & Lim et al. (2011) \\
\hline & $\begin{array}{l}\text { 4CL }(\text { A. thaliana }) \\
\text { STS }(V . \text { vinifera })\end{array}$ & - & & 1380 & \\
\hline & $\begin{array}{l}\text { 4CL ( } P . \text { crispum) } \\
\text { STS (A. hypogaea) }\end{array}$ & - & & 142 & \\
\hline & $\begin{array}{l}\text { 4CL }(P . \text { crispum }) \\
\text { STS }(V . \text { vinífera })\end{array}$ & - & & 610 & \\
\hline & $\begin{array}{l}\text { 4CL }(\text { A. thaliana }) \\
\text { STS }(V . \text { vinifera })\end{array}$ & - & $\begin{array}{l}p \text {-Coumaric acid }+ \\
\text { cerulenin }\end{array}$ & 2340 & \\
\hline E. coli $\mathrm{C} 41$ (DE3) & $\begin{array}{l}\text { TAL (Saccharothrix } \\
\text { espanaensis) } \\
\text { 4CL }(\text { Streptomyces } \\
\text { coelicolor }) \\
\text { STS }(\text { A. hypogaea })\end{array}$ & - & $p$-Coumaric acid & 1.4 & Choi et al. (2011) \\
\hline $\begin{array}{l}\text { E. coli BW25113 } \\
\text { (DE3) }\end{array}$ & $\begin{array}{l}\text { TAL }(R . \text { glutinis }) \\
\text { 4CL }(P . \text { crispum }) \\
\text { STS }(V . \text { vinifera })\end{array}$ & $\begin{array}{l}\text { Inactivation of tyrR and } \\
\text { deletion of trpED by } \\
\text { chromosomal integra- } \\
\text { tion }\end{array}$ & Glucose & 4.6 & Liu et al. (2016) \\
\hline E. coli BL21 (DE3) & $\begin{array}{l}\text { TAL }(R . \text { glutinis }) \\
\text { 4CL }(P . \text { crispum }) \\
\text { STS }(V . \text { vinifera }) \\
\text { mat } B \text { and } \text { matC } \\
\quad(R . \text { trifolii })\end{array}$ & - & L-Tyrosine & 35.02 & Wu et al. (2013) \\
\hline E. coli BL21 (DE3) & 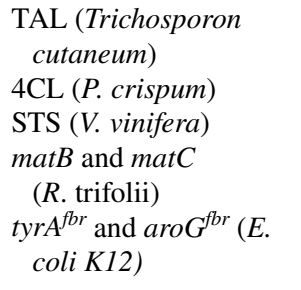 & $\begin{array}{l}\text { Down-regulation of } \\
f a b D, f a b H, f a b B, \\
\text { fabF, fabI }\end{array}$ & Glucose & 304.5 & Wu et al. (2017) \\
\hline \multirow{2}{*}{$\begin{array}{l}\text { E.coli } \\
\mathrm{W} \\
\left(\mathrm{pheA}^{-}\right) \mathrm{Rg} \\
\text { E.coli } \mathrm{W}-\mathrm{Vv}\end{array}$} & $\begin{array}{l}\text { TAL }(R . \text { glutinis }) \\
t k t A^{f b r} \text { and } \text { aro } G^{f b r} \\
\quad(\text { E. coli })\end{array}$ & Deletion of pheA & Glycerol & 22.58 & $\begin{array}{l}\text { Camacho-Zaragoza et al. } \\
\text { (2016) }\end{array}$ \\
\hline & $\begin{array}{l}\text { 4CL }(S . \text { coelicolor }) \\
\text { STS }(V \text {. vinífera })\end{array}$ & - & & & \\
\hline S. venezuelae DHS2001 & $\begin{array}{l}\text { STS }(\text { A. hypogaea }) \\
\text { 4CL }(S . \text { coelicolor })\end{array}$ & Deletion of $p k s$ & $p$-Coumaric acid & 0.4 & Park et al. (2009) \\
\hline L. lactis & $\begin{array}{l}\text { TAL, 4CL, STS, ACC } \\
\text { (from different sources) }\end{array}$ & & L-Tyrosine & $0.45-1.37$ & Gaspar et al. (2016) \\
\hline $\begin{array}{l}\text { L. lactis } \\
\text { Resv5 }\end{array}$ & $\begin{array}{l}\text { TAL }(\text { Flavobacterium } \\
\text { johnsoniae }) \\
\text { 4CL }(P . \text { crispum }) \\
\text { STS }(\text { A. hypogaea })\end{array}$ & - & L-Tyrosine & 2.25 & $\begin{array}{l}\text { Ferreira et al. (Manu- } \\
\text { script in preparation) }\end{array}$ \\
\hline
\end{tabular}


Table 1 (continued)

\begin{tabular}{|c|c|c|c|c|c|}
\hline Microorganism & $\begin{array}{l}\text { Heterologous enzymes/ } \\
\text { gene (source) }\end{array}$ & Host engineering & Substrate/precursor & Titer $\left(\mathrm{mg} \mathrm{L}^{-1}\right)$ & References \\
\hline C. glutamicum DelAro3 & $\begin{array}{l}\text { STS }(\text { A. hypogaea }) \\
\text { 4CL }(P . \text { crispum })\end{array}$ & $\begin{array}{l}\text { Deletion of } p h d B, p c a F \\
\text { and pobA }\end{array}$ & $\begin{array}{l}p \text {-Coumaric acid } \\
p \text {-coumaric acid }+ \\
\text { cerulenin }\end{array}$ & $\begin{array}{l}12 \\
158\end{array}$ & Kallscheuer et al. (2016) \\
\hline C. glutamicum DelAro4 & $\begin{array}{l}\text { TAL }(F . \text { johnsoniae }) \\
\text { 4CL }(\text { Petroselinum }) \\
\text { STS }(\text { A. hypogaea }) \\
\text { aroH }(\text { E. coli })\end{array}$ & $\begin{array}{l}\text { Deletion of } p h d B, \\
\quad p c a F, q s u B \text { and } p o b A\end{array}$ & $\begin{array}{l}\text { Glucose } \\
\text { Glucose }+ \text { cerulenin } \\
\text { Glucose }\left(40 \mathrm{~g} \mathrm{~L}^{-1}\right) \\
\text { Glucose }\left(80 \mathrm{~g} \mathrm{~L}^{-1}\right) \\
\text { Glucose }(\text { Fed-batch })\end{array}$ & $\begin{array}{l}12 \\
59 \\
4 \\
12 \\
7\end{array}$ & Braga et al. (2018a) \\
\hline S. cerevisiae W303-1A & $\begin{array}{l}\text { 4CL }(\text { A. thaliana }) \\
\text { STS }(\text { A. hypogaea })\end{array}$ & - & $p$-Coumaric acid & 3.1 & So-Yeon et al. (2011) \\
\hline S. cerevisiae WAT11 & $\begin{array}{l}\text { 4CL }(\text { A. thaliana }):: \mathrm{STS} \\
(V . \text { vinifera })\end{array}$ & - & $p$-Coumaric acid & 5.25 & Zhang et al. (2006) \\
\hline $\begin{array}{l}\text { Industrial Brazilian } S . \\
\text { cerevisiae strain }\end{array}$ & $\begin{array}{l}\text { 4CL }(\text { A. thaliana }) \\
\text { STS }(V . \text { vinifera })\end{array}$ & - & p-Coumaric acid & 391 & Sydor et al. (2010) \\
\hline $\begin{array}{l}\text { S. cerevisiae CEN. } \\
\text { PK102-5B }\end{array}$ & $\begin{array}{l}\text { TAL }(\text { Herpetosiphon } \\
\text { aurantiacus }) \\
\text { 4CL }(\text { A. thaliana }) \\
\text { VST }(\text { V. vinifera })\end{array}$ & $\begin{array}{l}\text { Overexpression of } \\
\text { aro } 4, \operatorname{aro} 7, \text { and } \operatorname{acc} 1\end{array}$ & $\begin{array}{l}\text { Glucose (fed-batch) } \\
\text { Ethanol (fed-batch) }\end{array}$ & $\begin{array}{l}415.65 \\
531.41\end{array}$ & Li et al. (2015) \\
\hline S. cerevisiae ST4990 & $\begin{array}{l}\text { PAL }(\text { A. thaliana }) \\
\text { C4H }(\text { A. thaliana }) \\
\text { 4CL }(\text { A. thaliana }) \\
\text { VST }(\text { V. vinifera }) \\
\text { ACS }(\text { Salmonella } \\
\text { enterica }) \\
\text { Overexpression of atr } 2 \\
\text { (A. thaliana) }\end{array}$ & $\begin{array}{l}\text { Overexpression of } \\
\text { aro } 4 \text {, aro } 7 \text {, and acc } 1 \\
\text { and deletion of aro } 10\end{array}$ & Glucose (Fed-batch) & 812 & Li et al. (2016) \\
\hline
\end{tabular}

4CL: 4-coumarate: CoA ligase; STS: stilbene synthases; TAL: tyrosine ammonia-lyase; ACC: acetyl-CoA carboxylase; F3H: flavanone 3b-hydroxylase; FLS: flavonol synthase; aroH/aroG: genes which encodes 3-deoxy-D-arabino-heptulosonate-7-phosphate synthase; matB: gene that encodes the malonyl-CoA synthetase; matC: genes that encode malonate carrier protein; VST: resveratrol synthase; ACS: acetyl-CoA synthase; $t y r A / p h e A$ : gene that encodes the chorismate mutase/prephenate dehydratase protein; pks: gene that encodes the pikromycin polyketide synthase protein; $f a b B / f a b F$ : gene that encodes the beta-ketoacyl-acp synthase I/II protein; $f a b D$ : gene that encodes the malonyl-CoA-acyl carrier protein transacylas; $f a b H$ : oxoacyl carrier protein synthase III; fabI: enoyl-[acyl-carrier protein] reductase I; aro4: gene that encodes DAHP synthase protein; aro7: genes that encodes the chorismate mutase; aro10: genes that encodes the phenylpyruvate decarboxylase; acc1: gene that encodes the acetyl-CoA carboxylase; atr2: gene that encodes the cytochrome P450 reductase; tyrR: transcriptional regulatory gene; tkyA: transketolase; trpED: gene that encodes the anthranilate synthetase protein; phdB: 3-hydroxyphenylpropanoyl-CoA dehydrogenase; $p c a F$ : $\beta$-ketoadipyl-CoA thiolase; $p o b A$ : 4-hydroxybenzoate 3-monooxygenase; qsuB: 3-dehydroshikimate dehydratase

(Lozoya et al. 1988). This strain produces $12 \mathrm{mg} \mathrm{L}^{-1}$ of resveratrol, with supplementation of $5 \mathrm{mM}$ of $p$-coumaric acid.

Besides selecting appropriate sources of enzymes, another approach available is to create enzymes with the desired functions through site-directed mutagenesis (Wang et al. 2012; Tee and Wong 2013). Protein engineering and mutagenesis of 4CL and STS have indeed been applied to improve resveratrol production capabilities in microorganisms. Zhang et al. (2015) increased the resveratrol production in $E$. coli using gene fusion technology. The authors applied the fusion of the enzyme 4CL::STS (4CL from $A$. thaliana and STS from A. hypogaea) that enabled a resveratrol production of $80.5 \mathrm{mg} \mathrm{L}^{-1}$ from $1 \mathrm{mM}$ p-coumaric acid. In another study, TAL, 4CL, chalcone synthase (CHS), and chalconeisomerase (CHI) have also been codon-optimized for $E$. coli expression which improved the resveratrol titer to $35 \mathrm{mg} \mathrm{L}^{-1}$ (Wu et al. 2013).

\section{Pathway engineering}

Most microorganisms, such as E. coli and C. glutamicum, do not have an endogenous phenylpropanoid pathway, thus the transformation of production strains with plant genes encoding metabolic enzymes is essential for de novo biosynthesis or bioconversion of resveratrol.

Designing optimal pathways for the production of resveratrol from inexpensive, safe and renewable resources, such as glucose and ethanol, is the first step in reconstructing the appropriate synthetic metabolic pathways in microorganisms. The two main goals within this step include the increase of the carbon flux into the shikimate pathway 
for the biosynthesis of the aromatic amino acids L-Phe or L-Tyr and the functional introduction of ammonia lyases for the efficient conversion of aromatic amino acids into phenylpropanoids.

Aromatic amino acids are produced from shikimate pathway in bacteria. However, this pathway is mostly regulated by feedback inhibition of allosterically controlled key enzymes (Kloosterman et al. 2003). The most common approaches to enhance the flux to the L-Phe and L-Tyr biosynthesis are the elimination of enzyme feedback inhibition regulation and transcriptional regulatory processes (Bulter et al. 2003; Lütke-Eversloh and Stephanopoulos 2007). The over-expression of native PEP synthetase (encoded by ppsA gene) redirects pyruvate to PEP for aromatic amino acid biosynthesis. Besides the over-expression of transketolases, especially TKT (encoded by $t k t A$ ), is an efficient approach for increasing the supply of E4P (Bulter et al. 2003; LütkeEversloh and Stephanopoulos 2007). The PEP levels could also be increased by repression or disruption of the global regulator gene $\operatorname{csr} A$, enhancing the production of aromatic amino acids (Bulter et al. 2003; Na et al. 2013).

The production of phenylpropenoic acids such as cinnamic acid or $p$-coumaric acid could be increased through the heterologous expression of PAL or TAL (Huang et al. 2013; Zhang and Stephanopoulos 2013). This is another bottleneck in the resveratrol production from glucose due to their low activity (Yang et al. 2015; Kallscheuer et al. 2016). Kallscheuer et al. (2016) constructed a C. glutamicum strain able to produce $60 \mathrm{mg} \mathrm{L}^{-1}$ resveratrol from glucose, after deregulation of the shikimate pathway and introduction of a heterologous TAL from Flavobacterium johnsoniae. The E. coli BW25113 (DE3) strain was also able to produce $4.6 \mathrm{mg} \mathrm{L}^{-1}$ of resveratrol from glucose after site-specific integration of the genes TAL, 4CL and STS (Liu et al. 2016). Soon after, Wu et al. (2017) applied various metabolic engineering strategies to produce resveratrol from glucose in $E$. coli. The pool of malonyl-CoA was increased with the introduction of the malonate assimilation pathway from $R$. trifolli and additionally the genes $f a b D, f a b H, f a b B, f a b F, f a b I$ were down-regulated to inactivate the malonyl-CoA consumption pathway. Furthermore, the expression level of the TAL enzyme was improved leading to a resveratrol production of $304.5 \mathrm{mg} \mathrm{L}^{-1}$.

In fact, the introduction of the entire de novo pathway is still a challenge due to low activity of TAL and PAL enzymes and also the low intracellular availability of malonyl-CoA.

\section{Central carbon flux redirection}

One of the major bottlenecks for resveratrol production in engineered microorganisms is the low intracellular availability of malonyl-CoA. The supplementation of the production medium with the main precursors, like L-Tyr, L-Phe, $p$-coumaric acid or cinnamic acid improves the production of resveratrol, since the availability of malonyl-CoA increases. Lim et al. (2011) and Wu et al. (2013) demonstrated the ability of E. coli strains to use $p$-coumaric acid and L-Tyr to produce 1308 and $35 \mathrm{mg} \mathrm{L}^{-1}$ resveratrol, respectively. However, it was observed that supplemented aromatic amino acids or phenylpropanoids were never completely converted to the corresponding polyphenols (Katsuyama et al. 2007; $\mathrm{Xu}$ et al. 2011; Kallscheuer et al. 2016; Milke et al. 2018). This precursor is required in the condensation reaction catalyzed by stilbene synthease (STS), where three molecules of cytosolic malonyl-CoA are sequentially added to one molecule of $p$-coumaroyl-CoA (Berg et al. 2002). However, malonyl-CoA is naturally synthesized in microorganisms for the production of fatty acids and phospholipids and only a very limited amount is available for the production of secondary metabolites (Takamura and Nomura 1988). Therefore it is of upmost importance to achieve a balance between the malonyl-CoA used for growth and resveratrol production. Significant efforts have been devoted to the development of different approaches to increase the intracellular pool of malonyl-CoA. One of the strategies is the medium supplementation with the natural fatty acid synthase-inhibiting antibiotic cerulenin (Santos et al. 2011; van Summeren-Wesenhagen and Marienhagen 2015). The addition of cerulenin, a covalent inhibitor of $f a b B$ and $f a b F$ genes, can greatly facilitate the accumulation of malonyl-CoA and thus increase the production of resveratrol (Lim et al. 2011; Finzel et al. 2015; Kallscheuer et al. 2016; Lu et al. 2016). Gaspar et al. (2016) observed that the addition of cerulenin after resveratrol induction resulted in a fourfold increase in the resveratrol concentration in L. lactis. The same behavior was also demonstrated by Lim et al. (2011) that also achieved a resveratrol production of $2.3 \mathrm{~g} \mathrm{~L}^{-1}$ by a two-step biotransformation from $p$-coumaric acid in presence of cerulenin, with an $E$. coli strain expressing heterologous genes coding for a $4 \mathrm{CL}$ from A. thaliana and for a STS from $V$. vinifera. Nevertheless, cerulenin is very expensive (Santos et al. 2011; de Fouchécour et al. 2018) and high cerulenin concentrations also reduced the cell growth rate possibly due to the detrimental effect of malonyl-CoA on cell growth (Subrahmanyam and Cronan1998) and thus cannot be used in large-scale fermentations (Lim et al. 2011; van Summeren-Wesenhagen and Marienhagen 2015; Milke et al. 2018). Instead, a strategy that focuses on rerouting native metabolic flows and uses stoichiometric modeling to improve malonyl-CoA availability is more appropriate for increasing resveratrol production (Fowler et al. 2009). One of these strategies is repression of $f a b$ operon using antisense RNA (asRNA) for down-regulation of fatty acids synthesis. Yang et al. (2015) expressed an asRNA targeting the mRNA of the malonyl-CoA-acyl carrier protein (ACP) transacylase gene $f a d D$ in E. coli and 
a 4.5-fold increase in the intracellular malonyl-CoA concentration was observed, leading to a 1.7-fold increase in the resveratrol titer $\left(268 \mathrm{mg} \mathrm{L}^{-1}\right)$. More recently clustered regularly interspaced short palindromic repeats interference (CRISPRi) system was used to down-regulate the expression of genes involved in fatty acid biosynthesis increasing the resveratrol titer by $290.5 \%$ (final titer $90 \mathrm{mg} \mathrm{L}^{-1}$ ) (Wu et al. 2017). A threefold increase in malonyl-CoA concentration was also achieved by over-expression of ACC, an enzyme involved in the acetate assimilation pathway responsible for the conversion of acetyl-CoA to malonyl-CoA (Zha et al. 2009). These $E$. coli strains were further engineered towards increased acetyl-CoA supply. Combination of over-expression of ACC, along with the elimination of pathways for acetate ( $p t a$ and $a c k A$ gene products) and ethanol formation $(a d h E)$, as well as over-expression of an acetate assimilation enzyme (acs), led to a 15-fold increase in malonyl-CoA level in E. coli (Zha et al. 2009).

Another strategy to increase the malonyl-CoA supply is the use of malonate assimilation pathway from $R$. trifolii, in which malonate is converted to malonyl-CoA by CoA ligation (An and Kim 1998). The matB and $m a t C$ genes encoding malonate-CoA synthase and malonate carrier proteins, respectively, allow the transport of supplemented malonate into the cell and its subsequent conversion to malonyl-CoA. However, supplementation of malonate in the medium is commercially unfavorable.

\section{Optimization of the production process}

Another important aspect to be considered is process engineering, since the optimization and balancing of microbial growth and product formation are key parameters for successful implementation of these processes. Braga et al. (2018a) studied the impact of cultivation conditions, namely substrate concentration on resveratrol production using $C$. glutamicum. They observed that an increase in glucose concentration from 40 to $80 \mathrm{~g} \mathrm{~L}^{-1}$ leads to an increase in the resveratrol titer from 4 to $12 \mathrm{mg} \mathrm{L}^{-1}$ (Braga et al. 2018a).

Another parameter that shows a huge impact on resveratrol biosynthesis and stability is the dissolved oxygen concentration. Oxygen is critical for aerobic growth of bacteria and the synthesis of resveratrol; however, an excessive amount of dissolved oxygen may oxidize resveratrol since it was described that the resveratrol stability in solution is affected by high oxygen concentrations and light (LucasAbellán et al. 2007; Trošt et al. 2009). This behavior has also been described by Braga et al. (2018b). They observed that high oxygen concentrations in the bioreactor affected negatively the resveratrol titers with $C$. glutamicum.

Co-culture strategies have recently been highlighted since polyphenols, as resveratrol, are produced from complex biosynthetic pathways. With these strategies it is possible to use multiple strains capable of metabolizing different substrates or producing different products, and the whole pathway can be divided and introduced into each strain working as a module (Zhou et al. 2015). This strategy was recently described by Camacho-Zaragoza et al. (2016) for resveratrol production with a co-culture of two different $E$. coli strains, with a final titer of $22.6 \mathrm{mg} \mathrm{L}^{-1}$ of resveratrol using glycerol as carbon source. They reduced the metabolic burden of each strain with a distribution of the biochemical pathway into two strains.

The dependence on precursor feeding (typically L-Tyr, LPhe and $p$-coumaric acid) is also a drawback in this process, due to the high market price of these compounds (Santos et al. 2011). Nevertheless, the development of engineered strains able to convert cheaper substrates, such as glucose, may solve this problem ( $\mathrm{Li}$ et al. 2015; Wu et al. 2017).

The compounds used as precursors ( $p$-coumaric acid, L-Tyr or L-Phe) present some toxicity to the cells at high concentrations and alternative strategies should be considered such as the addition of lower substrate concentrations at the beginning of the experiment and further additions following their consumption rate (step-wise fed batch) (Watts et al. 2006; Huang et al. 2013; Zhang and Stephanopoulos 2013). However, resveratrol itself could also be toxic to the cells at high concentrations and the application of in situ product removal strategies will lead to a continuous resveratrol removal from the fermentation broth, without falling into toxicity limitations due to an excess of resveratrol in the system and also protecting the product from oxidative degradation, and facilitating a further downstream processing (Hua et al. 2007). Braga et al. (2018b) applied in situ product removal technique for resveratrol production with C. glutamicum using Amberlite XAD-7HP as adsorbent and observed an increase ranging from 75 to $95 \%$ in the amount of extracellular resveratrol produced. With this strategy they can avoid the potential problems with the toxicity of resveratrol to the cells and also prevents undesired oxidation.

\section{Conclusions and future prospective}

During the last years, the biotechnological production of resveratrol has attracted a great deal of attention. Research has been focused on the potential applications for human benefit as well as to understand its biosynthetic pathways in $\mathrm{V}$. vinifera and its heterologous production in bacteria and yeasts. Although, the scientific community has dedicated time and efforts around the production of "natural" polyphenols, the overall productivity is still very low which is a drawback for their industrial production. The different genes involved in the biosynthesis of resveratrol have been identified and characterized and recent developments in synthetic biology 
and molecular biology enabled its heterologous production. However the major limitations are still the low activity of plant-derived enzymes in the heterologous hosts and the insufficient supply of precursor molecules by the microbial metabolism. The best candidate enzymes for each step of the resveratrol production pathway should be studied to find the most adequate conditions to convert the metabolic intermediates into the desired products, and avoid the accumulation of these intermediates, to promote the final product synthesis and avoid their toxicity to the bacterial host. The fine tuning of expression and balancing the entire pathway with the central metabolism of the cell is also a key issue.

Nevertheless, the application of metabolic engineering, system and synthetic biology tools for strain-design, with process engineering strategies may address the hurdles of inefficient production of resveratrol in microorganisms. We believe that combining these approaches, the heterologous production of resveratrol could be competitive with current processes of chemical synthesis and extraction from plants. In a near future, scale-up to industrial processes will be achieved and optimized in order to develop a sustainable production of resveratrol that should provide a basis for the future improvement of microbial strains that synthesize other useful plant metabolites. The question now is when will the microbial production of resveratrol become economically feasible.

Acknowledgements We would like to thank the European Union Framework Program 7 "BacHBerry" (http://www.bachberry.eu), Project No. FP7-613793 for financial support, the Portuguese Foundation for Science and Technology (FCT) under the scope of the strategic funding of UID/BIO/04469 unit, COMPETE 2020 (POCI-01-0145FEDER-006684) and BiotecNorte operation (NORTE-01-0145FEDER-000004) funded by the European Regional Development Fund under the scope of Norte2020 - Programa Operacional Regional do Norte.

\section{Compliance with ethical standards}

Conflict of interest The authors declared that they have no conflict of interest.

\section{References}

Abe I, Watanabe T, Noguchi H (2004) Enzymatic formation of longchain polyketide pyrones by plant type III polyketide synthases. Phytochemistry 65:2447-2453. https://doi.org/10.1016/j.phyto chem.2004.08.005

Afonso MS, Ferreira S, Domingues FC, Silva F (2015) Resveratrol production in bioreactor: assessment of cell physiological states and plasmid segregational stability. Biotechnol Rep 5:7-13. https ://doi.org/10.1016/j.btre.2014.10.008

Aggarwal BB, Bhardwaj A, Aggarwal RS et al (2004) Role of resveratrol in prevention and therapy of cancer: preclinical and clinical studies. Anticancer Res 24.5A:2783-2840
An JH, Kim YS (1998) A gene cluster encoding malonyl-CoA decarboxylase (MatA), malonyl-CoA synthetase (MatB) and a putative dicarboxylate carrier protein (MatC) in Rhizobium trifolii. Cloning, sequencing, and expression of the enzymes in Escherichia coli. Eur J Biochem 257:395-402. https://doi.org/10.104 6/j.1432-1327.1998.2570395.x

Anekonda TS (2006) Resveratrol-A boon for treating Alzheimer's disease? Brain Res Rev 52:316-326. https://doi.org/10.1016/j.brain resrev.2006.04.004

Bauer JH, Goupil S, Garber GB, Helfand SL (2004) An accelerated assay for the identification of lifespan-extending interventions in Drosophila melanogaster. Proc Natl Acad Sci 101:12980-12985. https://doi.org/10.1073/pnas.0403493101

Baur JA, Sinclair DA (2006) Therapeutic potential of resveratrol: the in vivo evidence. Nat Rev Drug Discov 5:493-506. https://doi. org/10.1038/nrd2060

Bavaresco L, Petegolli D, Cantù E et al (1997) Elicitation and accumulation of stilbene phytoalexins in grapevine berries infected by Botrytis cinerea. Vitis 36:77-83

Beekwilder J, Wolswinkel R, Jonker $\mathrm{H}$ et al (2006) Production of resveratrol in recombinant microorganisms. Appl Environ Microbiol 72:5670-5672. https://doi.org/10.1128/AEM.00609-06

Berg J, Tymoczko J, Stryer L (2002) Biochemistry. New York, New York, p 10010

Blond J, Denis M, Bezard J (1995) Antioxidant action of resveratrol in lipid peroxidation. Sci Aliments 15:347-358

Braga A, Oliveira J, Silva R et al (2018a) Impact of the cultivation strategy on resveratrol production from glucose in engineered Corynebacterium glutamicum. J Biotechnol 265:70-75. https:// doi.org/10.1016/j.jbiotec.2017.11.006

Braga A, Silva M, Oliveira J et al (2018b) An adsorptive bioprocess for production and recovery of resveratrol with Corynebacterium glutamicum. J Chem Technol Biotechnol. https://doi.org/10.1002/ jctb.5538

Bulter T, Bernstein JR, Liao JC (2003) A perspective of metabolic engineering strategies: moving up the systems hierarchy. Biotechnol Bioeng 84:815-821. https://doi.org/10.1002/bit.10845

Camacho-Zaragoza JM, Hernández-Chávez G, Moreno-Avitia F et al (2016) Engineering of a microbial coculture of Escherichia coli strains for the biosynthesis of resveratrol. Microb Cell Fact 15:163. https://doi.org/10.1186/s12934-016-0562-z

Choi O, Wu C-Z, Kang SY et al (2011) Biosynthesis of plant-specific phenylpropanoids by construction of an artificial biosynthetic pathway in Escherichia coli. J Ind Microbiol Biotechnol 38:16571665. https://doi.org/10.1007/s10295-011-0954-3

de Fouchécour F, Sánchez-Castañeda A-K, Saulou-Bérion C, Spinnler H (2018) Process engineering for microbial production of 3-hydroxypropionic acid. Biotechnol Adv. https://doi. org/10.1016/j.biotechadv.2018.03.020

Du J, Shao Z, Zhao H (2013) Engineering microbial factories for synthesis of value-added products. J Ind Microbiol Biotechnol 38:873-890. https://doi.org/10.1109/TMI.2012.2196707

Finzel K, Lee DJ, Burkart MD (2015) Using modern tools to probe the structure-function relationship of fatty acid synthases. ChemBioChem 16:528-547. https://doi.org/10.1002/cbic.201402578

Fowler ZL, Gikandi WW, Koffas MAG (2009) Increased malonyl coenzyme A biosynthesis by tuning the Escherichia coli metabolic network and its application to flavanone production. Appl Environ Microbiol 75:5831-5839. https://doi.org/10.1128/AEM.00270-09

Frankel EN, Waterhouse AL, Kinsella JE (1993) Inhibition of human LDL oxidation by resveratrol. Lancet 341:1103-1104. https://doi. org/10.1016/0140-6736(93)92472-6

Gaspar P, Dudnik A, Neves AR, Föster J (2016) Engineering Lactococcus lactis for stilbene production. In: Abstract from 28th International Conference on Polyphenols 2016. Vienna, Austria 
Halls C, Yu O (2008) Potential for metabolic engineering of resveratrol biosynthesis. Trends Biotechnol 26:77-81. https://doi. org/10.1016/j.tibtech.2007.11.002

Hamberger B, Hahlbrock K (2004) The 4-coumarate:CoA ligase gene family in Arabidopsis thaliana comprises one rare, sinapate-activating and three commonly occurring isoenzymes. Proc Natl Acad Sci 101:2209-2214. https://doi.org/10.1073/pnas.0307307101

Hua D, Ma C, Song L et al (2007) Enhanced vanillin production from ferulic acid using adsorbent resin. Appl Microbiol Biotechnol 74:783-790. https://doi.org/10.1007/s00253-006-0735-5

Huang Q, Lin Y, Yan Y (2013) Caffeic acid production enhancement by engineering a phenylalanine over-producing Escherichia coli strain. Biotechnol Bioeng 110:3188-3196. https://doi. org/10.1002/bit.24988

Hubbard BP, Sinclair DA (2014) Small molecule SIRT1 activators for the treatment of aging and age-related diseases. Trends Pharmacol Sci 35:146-154. https://doi.org/10.1016/j.tips.2013.12.004

Jiang H, Wood KV, Morgan J (2005) Metabolic engineering of the phenylpropanoid pathway in Saccharomyces cerevisiae. Appl Environ Microbiol 71:2962-2969. https://doi.org/10.1128/AEM.71.6.2962

Kallscheuer N, Vogt M, Stenzel A et al (2016) Construction of a Corynebacterium glutamicum platform strain for the production of stilbenes and (2S)-flavanones. Metab Eng 38:47-55. https://doi. org/10.1016/j.ymben.2016.06.003

Katsuyama Y, Funa N, Horinouchi S (2007) Precursor-directed biosynthesis of stilbene methyl ethers in Escherichia coli. Biotechnol J 2:1286-1293. https://doi.org/10.1002/biot.200700098

Kiselev KV (2011) Perspectives for production and application of resveratrol. Appl Microbiol Biotechnol 90:417-425. https://doi. org/10.1007/s00253-011-3184-8

Kloosterman H, Hessels GI, Vrijbloed JW et al (2003) (De)regulation of key enzyme steps in the shikimate pathway and phenylalanine-specific pathway of the actinomycete Amycolatopsis methanolica. Microbiology 149:3321-3330. https://doi.org/10.1099/ mic.0.26494-0

Kundu JK, Surh YJ (2008) Cancer chemopreventive and therapeutic potential of resveratrol: mechanistic perspectives. Cancer Lett 269:243-261. https://doi.org/10.1016/j.canlet.2008.03.057

Li M, Kildegaard KR, Chen Y et al (2015) De novo production of resveratrol from glucose or ethanol by engineered Saccharomyces cerevisiae. Metab Eng 32:1-11. https://doi.org/10.1016/j.ymben .2015 .08 .007

Li M, Schneider K, Kristensen M et al (2016) Engineering yeast for high-level production of stilbenoid antioxidants. Sci Rep 6:1-8. https://doi.org/10.1038/srep36827

Light SH, Halavaty AS, Minasov G et al (2012) Structural analysis of a 3-deoxy-D-arabino-heptulosonate 7-phosphate synthase with an $\mathrm{N}$-terminal chorismate mutase-like regulatory domain. Protein Sci 21:887-895. https://doi.org/10.1002/pro.2075

Lim CG, Fowler ZL, Hueller T et al (2011) High-yield resveratrol production in engineered Escherichia coli. Appl Environ Microbiol 77:3451-3460. https://doi.org/10.1128/AEM.02186-10

Liu X, Lin J, Hu H et al (2016) De novo biosynthesis of resveratrol by site-specific integration of heterologous genes in Escherichia coli. FEMS Microbiol Lett 363:1-5. https://doi.org/10.1093/femsl e/fnw061

Lozoya E, Hoffmann H, Douglas C et al (1988) Primary structures and catalytic properties of isoenzymes encoded by the two 4-coumarate:CoA ligase genes in parsley. Eur J Biochem 176:661-667. https://doi.org/10.1111/j.1432-1033.1988.tb143 28.X

Lu Y, Shao D, Shi J et al (2016) Strategies for enhancing resveratrol production and the expression of pathway enzymes. Appl Microbiol Biotechnol 100:7407-7421. https://doi.org/10.1007/s0025 3-016-7723-1
Lucas-Abellán C, Fortea I, López-Nicolás JM, Núñez-Delicado E (2007) Cyclodextrins as resveratrol carrier system. Food Chem 104:39-44. https://doi.org/10.1016/j.foodchem.2006.10.068

Lütke-Eversloh T, Stephanopoulos G (2007) L-Tyrosine production by deregulated strains of Escherichia coli. Appl Microbiol Biotechnol 75:103-110. https://doi.org/10.1007/s00253-006-0792-9

Maeda H, Dudareva N (2012) The Shikimate pathway and aromatic amino acid biosynthesis in plants. Annu Rev Plant Biol 63:73105. https://doi.org/10.1146/annurev-arplant-042811-105439

Makrides SC (1996) Strategies for achieving high-level expression of genes in Escherichia coli. Microbiol Rev 60:512-538

Mei YZ, Liu RX, Wang DP et al (2015) Biocatalysis and biotransformation of resveratrol in microorganisms. Biotechnol Lett 37:9-18. https://doi.org/10.1007/s10529-014-1651-x

Milke L, Aschenbrenner J, Marienhagen J, Kallscheuer N (2018) Production of plant-derived polyphenols in microorganisms: current state and perspectives. Appl Microbiol Biotechnol. https://doi. org/10.1007/s00253-018-8747-5

Morita H, Noguchi H, Schröder J, Abe I (2001) Novel polyketides synthesized with a higher plant stilbene synthase. Eur J Biochem 268:3759-3766. https://doi.org/10.1046/j.1432-1327.2001.02289

Na D, Yoo SM, Chung H et al (2013) Metabolic engineering of Escherichia coli using synthetic small regulatory RNAs. Nat Biotechnol 31:170-174. https://doi.org/10.1038/nbt.2461

Nonomura S, Kanagawa H, Makimoto A (1963) Chemical constituents of polygonaceous plants. I. Studies on the components of Ko-J O-Kon. (Polygonum cuspidatum Sieb. Et Zucc.). Yakugaku Zasshi 83:988-990

Park SR, Yoon JA, Paik JH et al (2009) Engineering of plant-specific phenylpropanoids biosynthesis in Streptomyces venezuelae. J Biotechnol 141:181-188. https://doi.org/10.1016/j.jbiot ec.2009.03.013

Quideau S, Deffieux D, Douat-Casassus C, Pouységu L (2011) Plant polyphenols: chemical properties, biological activities, and synthesis. Angew Chemie-Int Ed 50:586-621. https://doi. org/10.1002/anie.201000044

Rodrigues JL, Prather KLJ, Kluskens LD, Rodrigues LR (2015) Heterologous production of curcuminoids. Microbiol Mol Biol Rev 79:39-60. https://doi.org/10.1128/MMBR.00031-14

Rosano GL, Ceccarelli EA (2014) Recombinant protein expression in Escherichia coli: advances and challenges. Front Microbiol 5:1-17. https://doi.org/10.3389/fmicb.2014.00172

Santos CNS, Koffas M, Stephanopoulos G (2011) Optimization of a heterologous pathway for the production of flavonoids from glucose. Metab Eng 13:392-400. https://doi.org/10.1016/j.ymben .2011 .02 .002

Schroeder AC, Kumaran S, Hicks LM et al (2008) Contributions of conserved serine and tyrosine residues to catalysis, ligand binding, and cofactor processing in the active site of tyrosine ammonia lyase. Phytochemistry 69:1496-1506. https://doi.org/10.1016/j. phytochem.2008.02.007

Sharma S, Kulkarni SK, Chopra K (2007) Effect of resveratrol, a polyphenolic phytoalexin, on thermal hyperalgesia in a mouse model of diabetic neuropathic pain. Fundam Clin Pharmacol 21:89-94. https://doi.org/10.1111/j.1472-8206.2006.00455.x

Shin SY, Han NS, Park YC et al (2011) Production of resveratrol from $p$-coumaric acid in recombinant Saccharomyces cerevisiae expressing 4-coumarate:coenzyme A ligase and stilbene synthase genes. Enzyme Microb Technol 48:48-53. https://doi. org/10.1016/j.enzmictec.2010.09.004

So-Yeon S, Nam SH, Yong-Cheol P et al (2011) Production of resveratrol from $p$-coumaric acid in recombinant Saccharomyces cerevisiae expressing 4-coumarate:coenzyme A ligase and stilbene 
synthase genes. Enzyme Microb Technol 48:48-53. https://doi. org/10.1016/j.enzmictec.2010.09.004

Subrahmanyam S Jr, Cronan JE (1998) Overproduction of a functional fatty acid biosynthetic enzyme blocks fatty acid synthesis in Escherichia coli. J Bacteriol 180:4596-4602

Sydor T, Schaffer S, Boles E (2010) Considerable increase in resveratrol production by recombinant industrial yeast strains with use of rich medium. Appl Environ Microbiol 76:3361-3363. https:// doi.org/10.1128/AEM.02796-09

Takamura Y, Nomura G (1988) Changes in the intracellular concentration of Acetyl-CoA and Malonyl-CoA in relation to the carbon and energy metabolism of Escherichia coli K12. J Gen Microbiol $134: 2249-2253$

Takaoka M (1939) Resveratrol, a new phenolic compound, from Veratrumgrandiflorum. J Chem Soc Japan 60:1090-1100

Tee KL, Wong TS (2013) Polishing the craft of genetic diversity creation in directed evolution. Biotechnol Adv 31:1707-1721. https ://doi.org/10.1016/j.biotechadv.2013.08.021

Theisen M, Liao JC (2016) Industrial biotechnology: Escherichia coli as a host. In: Industrial biotechnology. Wiley, New York, pp 149-181

Trošt K, Golc-Wondra A, Prošek M (2009) Degradation of polyphenolic antioxidants in blueberry nectar aseptically filled in PET. Acta Chim Slov 56:494-502

van Summeren-Wesenhagen PV, Marienhagen J (2013) Putting bugs to the blush: metabolic engineering for phenylpropanoid-derived products in microorganisms. Bioengineered 4:355-362. https:// doi.org/10.4161/bioe.23885

van Summeren-Wesenhagen PV, Marienhagen J (2015) Metabolic engineering of Escherichia coli for the synthesis of the plant polyphenol pinosylvin. Appl Environ Microbiol 81:840-849. https://doi. org/10.1128/AEM.02966-14

Vannelli T, Wei Qi W, Sweigard J et al (2007) Production of $p$-hydroxycinnamic acid from glucose in Saccharomyces cerevisiae and Escherichia coli by expression of heterologous genes from plants and fungi. Metab Eng 9:142-151. https://doi.org/10.1016/j.ymben .2006.11.001

Vingtdeux V, Dreses-Werringloer U, Zhao H et al (2008) Therapeutic potential of resveratrol in Alzheimer's disease. BMC Neurosci 9:1-5. https://doi.org/10.1186/1471-2202-9-S2-S6

Viswanathan M, Kim SK, Berdichevsky A, Guarente L (2005) A role for SIR-2.1 regulation of ER stress response genes in determining C. elegans life span. Dev Cell 9:605-615. https://doi. org/10.1016/j.devcel.2005.09.017

Wang J, Ho L, Zhao Z et al (2006) Moderate consumption of Cabernet Sauvignon attenuates A neuropathology in a mouse model of Alzheimer's disease. FASEB J 20:2313-2320. https://doi. org/10.1096/fj.06-6281com

Wang T, Ma X, Du G, Chen J (2012) Overview of regulatory strategies and molecular elements in metabolic engineering of bacteria.
Mol Biotechnol 52:300-308. https://doi.org/10.1007/s1203 3-012-9514-y

Wang J, Yang Y, Yan Y (2018) Bioproduction of resveratrol. In: Biotechnology of natural products. Springer, Cham, pp 61-79

Watts KT, Lee PC, Schmidt-Dannert C (2006) Biosynthesis of plant-specific stilbene polyketides in metabolically engineered Escherichia coli. BMC Biotechnol 6:1-12. https://doi. org/10.1186/1472-6750-6-22

Wu J, Liu P, Fan Y et al (2013) Multivariate modular metabolic engineering of Escherichia coli to produce resveratrol from 1-tyrosine. J Biotechnol 167:404-411. https://doi.org/10.1016/j.jbiot ec.2013.07.030

Wu J, Zhou P, Zhang X, Dong M (2017) Efficient de novo synthesis of resveratrol by metabolically engineered Escherichia coli. J Ind Microbiol Biotechnol 44:1083-1095. https://doi.org/10.1007/ s10295-017-1937-9

Xu P, Ranganathan S, Fowler ZL et al (2011) Genome-scale metabolic network modeling results in minimal interventions that cooperatively force carbon flux towards malonyl-CoA. Metab Eng 13:578-587. https://doi.org/10.1016/j.ymben.2011.06.008

Yang X, Li X, Ren J (2014) From French Paradox to cancer treatment: anti-cancer activities and mechanisms of resveratrol. AntiCancer Agents Med Chem (formerly Curr Med Chem Agents) 14:806-825

Yang Y, Lin Y, Li L et al (2015) Regulating malonyl-CoA metabolism via synthetic antisense RNAs for enhanced biosynthesis of natural products. Metab Eng 29:217-226. https://doi.org/10.1016/j.ymben .2015 .03 .018

Yesilirmak F, Sayers Z (2009) Heterelogous expression of plant genes. Int J Plant Genom. https://doi.org/10.1155/2009/296482

Zha W, Rubin-Pitel SB, Shao Z, Zhao H (2009) Improving cellular malonyl-CoA level in Escherichia coli via metabolic engineering. Metab Eng 11:192-198. https://doi.org/10.1016/j.ymben .2009.01.005

Zhang H, Stephanopoulos G (2013) Engineering E. coli for caffeic acid biosynthesis from renewable sugars. Appl Microbiol Biotechnol 97:3333-3341. https://doi.org/10.1007/s00253-012-4544-8

Zhang Y, Li SZ, Li J et al (2006) Using unnatural protein fusions to engineer resveratrol biosynthesis in yeast and mammalian cells. $\mathbf{J}$ Am Chem Soc 128:13030-13031. https://doi.org/10.1021/ja062 2094

Zhang E, Guo X, Meng Z et al (2015) Construction, expression, and characterization of Arabidopsis thaliana 4CL and Arachis hypogaea RS fusion gene 4CL::RS in Escherichia coli. World J Microbiol Biotechnol 31:1379-1385. https://doi.org/10.1007/ s11274-015-1889-z1

Zhou K, Qiao K, Edgar S, Stephanopoulo G (2015) Distributing a metabolic pathway among a microbial consortium enhances production of natural products. Nat Biotechnol 33:377-383 